\title{
The effect of temperature on growth and development of cultivars of radish (Raphanus sativus L. var. radicula Pers.) under summer conditions
}

\section{Nieuwhof}

Institute for Horticultural Plant Breeding (IVT), Wageningen, the Netherlands

Key words: Raphanus sativus var. radicula, radish, cultivars, temperature, harvest time, growth, development, light conditions, genotype $\times$ environment interactions, breeding

\section{Summary}

Seven radish cultivars and strains were sown out in temperature controlled glasshouses at $10,14,17,20,23$ and $26^{\circ} \mathrm{C}$ at long days and high light intensities.

Maximum leaf and dry matter production occurred at 20 and $23{ }^{\circ} \mathrm{C}$, maximum root growth initially at 20 and $23{ }^{\circ} \mathrm{C}$, but later at lower temperatures.

Between the cultivars differences in rate of leaf and root growth were observed. Also some cultivar $\times$ environment (temperature, harvest time) interactions were assessed, but no cultivar $\times$ season interaction. Thus it appears possible, at least with the material tested, to select radish in summer for growing under winter conditions.

\section{Introduction}

In 1974 research was carried out on the effect of temperature on growth and development of a number of radish cultivars in autumn (Nieuwhof, 1976). The same cultivars were sown out in summer at a range of temperatures to study their performance at long days and high light intensities and to find out if genotype $x$ environment interactions occur. The results of this research are reported in this paper.

\section{Material and methods}

The experiment included the same cultivars as the autumn experiment, viz 'Champion', 'Cherry Belle', 'Kader', 'Rota' and 'Ronde Helderrode'. Of this last, two strains were used, viz 'Robijn' and 'Triplo'. The strain 'Neoro' was replaced by the early cultivar 'Robino'. 'Champion' is a summer cultivar, the others are used for early production under glass or in the open. 
The experiment was carried out in temperature-controlled glasshouses of the IVT phytotron at $10,14,17,20,23$ and $26^{\circ} \mathrm{C}$ under natural light conditions. Sowing was done on 5 July 1977. A randomized block design was used with 5 replications, plots of 1 row with a length of $1 \mathrm{~m}$, a distance between rows of $11 \mathrm{~cm}$ and between plants of about $2 \mathrm{~cm}$.

The dates of seedling emergence were recorded. On 18 and 25 July and 1, 8 and 15 August at each temperature one plot of each cultivar or strain was harvested and fresh leaf weight (including cotyledons) and root weight were determined. The number of plants harvested per plot varied little and was on an average 32 .

At the first, third and fifth harvests at each temperature samples of 10 plants of 'Cherry Belle', 'Kader' and 'Rota' (the same cultivars as used for this purpose in the autumn experiment) were taken for determinations of dry matter content (\% DM) of leaves and roots.

The data on irradiance were obtained from the Department of Physics and Meteorology of the Agricultural University at Wageningen.

\section{Results}

\section{Seedling emergence}

The emergence of seedlings was earlier at higher temperatures, but differences between temperatures were small. At $26^{\circ} \mathrm{C}$ seedlings emerged on an average after 3.2 days and at $10{ }^{\circ} \mathrm{C}$ after 5.1 days.

At all temperatures 'Kader' emerged somewhat later and 'Robijn' somewhat earlier than the other numbers.

\section{Growth of leaves}

From Fig. 1 it can be seen that for $w$ (= fresh leaf weight): $w\left(20^{\circ} \mathrm{C}\right) \geqslant w\left(23^{\circ} \mathrm{C}\right)$ $>w\left(26^{\circ} \mathrm{C}\right) \geqslant w\left(17^{\circ} \mathrm{C}\right)>w\left(14^{\circ} \mathrm{C}\right)>w\left(10^{\circ} \mathrm{C}\right)$.

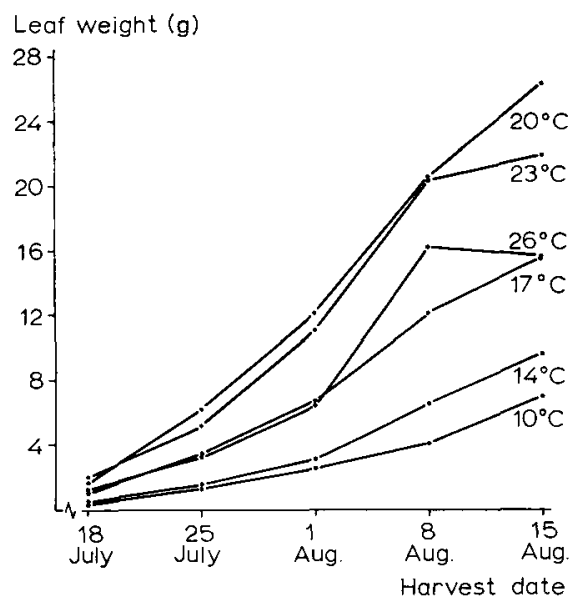

Fig. 1. Effect of temperature on fresh leaf weight at 5 harvest dates (averages of 7 cultivars/strains). 


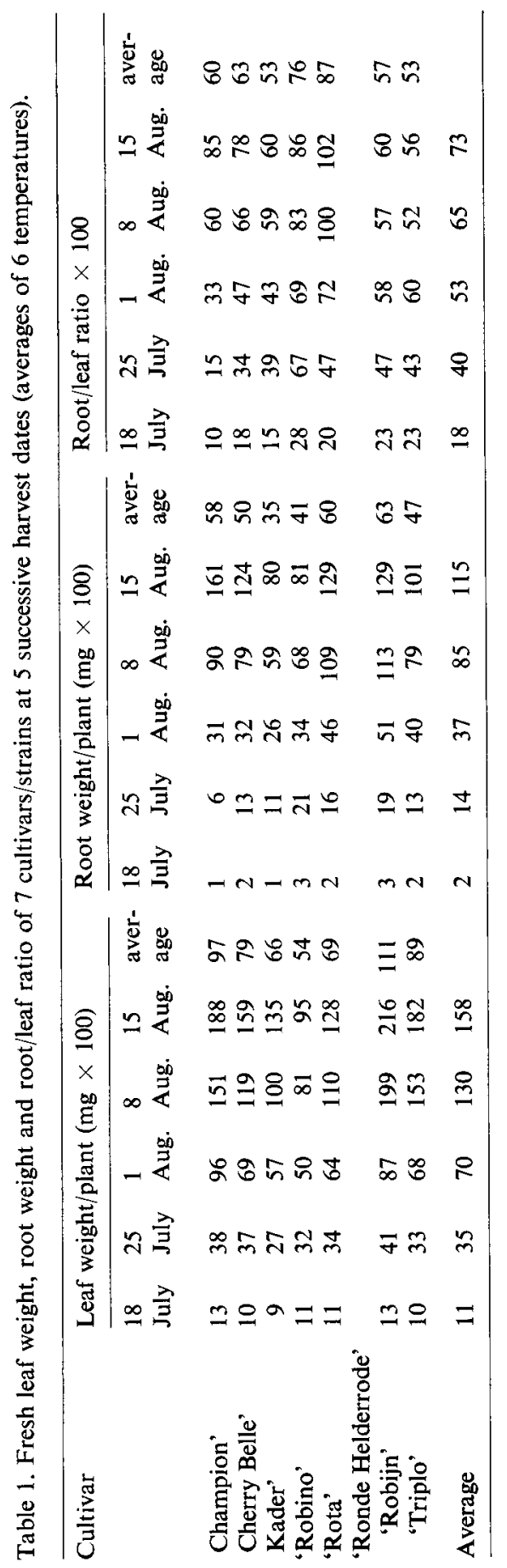




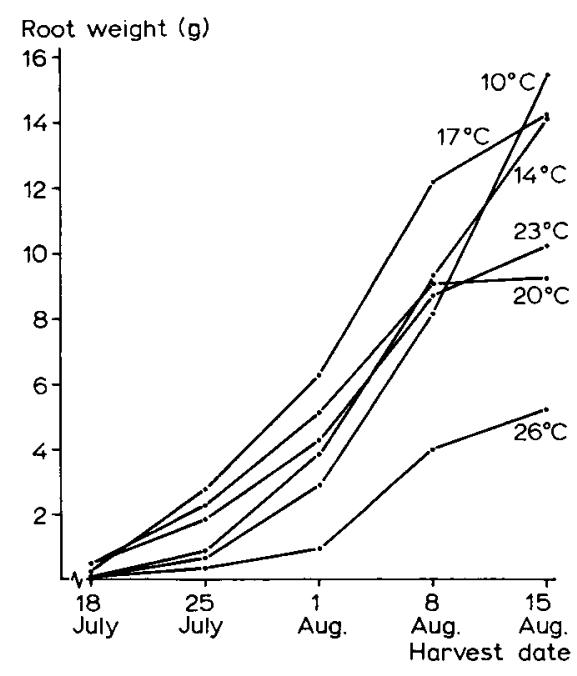

Fig. 2. Effect of temperature on fresh root weight at 5 harvest dates (averages of 7 cultivars/strains).

Between cultivars distinct average differences for fresh leaf weight occurred, 'Robijn' producing the heaviest and 'Robino' the lowest (Table 1). For this character an interaction with harvest date was assessed: at the first harvest leaf weight of 'Triplo' was as low as that of 'Robino', but afterwards the increase in leaf weight of 'Triplo' was much greater than that of 'Robino'. For leaf weight no interaction cultivar $\times$ temperature was found.

\section{Growth of roots}

At the first harvest - when hardly any root thickening was observed - the optimum temperatures for fresh root weight were 20 to $23^{\circ} \mathrm{C}$, and later on $17^{\circ} \mathrm{C}$. Root thickening at 10 and $14{ }^{\circ} \mathrm{C}$ was at first very slow, but at the fourth harvest reached the same level as at 20 and $23{ }^{\circ} \mathrm{C}$, and at the last harvest that of $17^{\circ} \mathrm{C}$. At all harvests slowest root growth was recorded at $26^{\circ} \mathrm{C}$ (Fig. 2).

Many plants at $17^{\circ} \mathrm{C}$ were already mature at the second harvest (20 days after sowing out), and a somewhat smaller number at 20 and $23{ }^{\circ} \mathrm{C}$. At the third harvest most plants at 17,20 and $23{ }^{\circ} \mathrm{C}$ were over-mature and those at 10 and $14{ }^{\circ} \mathrm{C}$ mature or nearly so.

'Rota' and 'Robijn' produced on an average the heaviest roots and 'Kader' and 'Robino' the lightest (Table 1). However, some interactions occurred:

- 'Robino' was characterized by a very quick root growth after sowing. At the second harvest this cultivar produced the most mature roots, but afterwards root growth was relatively slow compared with the other cultivars.

- In contrast, root growth of the summer cultivar 'Champion' was at first slow, but after the second harvest root thickening was faster than with the other cultivars, particularly at 20 and $23{ }^{\circ} \mathrm{C}$, but later on also at lower temperatures.

The optimum temperature for 'Champion' was higher (at the third, fourth and fifth harvests 23,20 and $17^{\circ} \mathrm{C}$, respectively) than for other cultivars (at these 3 harvests $17-20^{\circ} \mathrm{C}, 14-17^{\circ} \mathrm{C}$ and $10-14{ }^{\circ} \mathrm{C}$, respectively). 


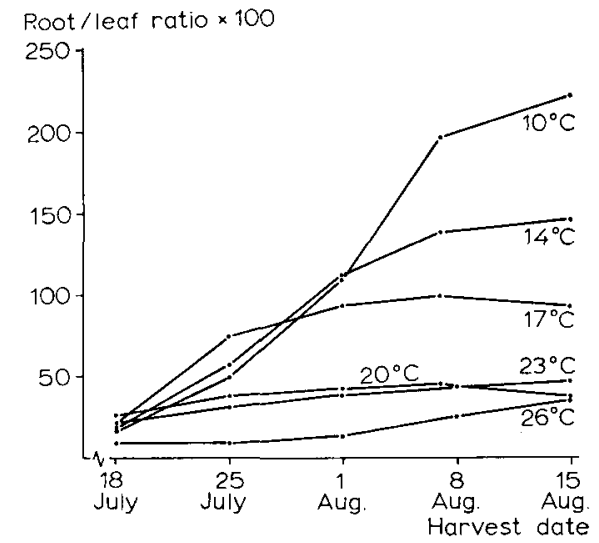

Fig. 3. Effect of temperature on root/leaf ratio at 5 harvest dates (averages of 7 cultivars/ strains).

\section{Root/leaf ratio $\times 100$}

This ratio increased at lower temperatures and later harvests (Fig. 3). At the 3 highest temperatures averages were never above 50 , and at 17,14 and $10^{\circ} \mathrm{C}$ the average ratios at the end of the experiment were 93, 146 and 220, respectively.

At the date of maturity this ratio was also increasing at lower temperatures (at $20 / 23{ }^{\circ} \mathrm{C}, 17^{\circ} \mathrm{C}$ and $10 / 14^{\circ} \mathrm{C}, 35-40,75$ and 130 respectively).

'Rota' and 'Robino' had on an average the highest root/leaf ratios (Table 1 ).

Dry matter content (Fig. 4)

At all 3 harvest dates the average \% DM of the leaves was 6.6. The average \% DM

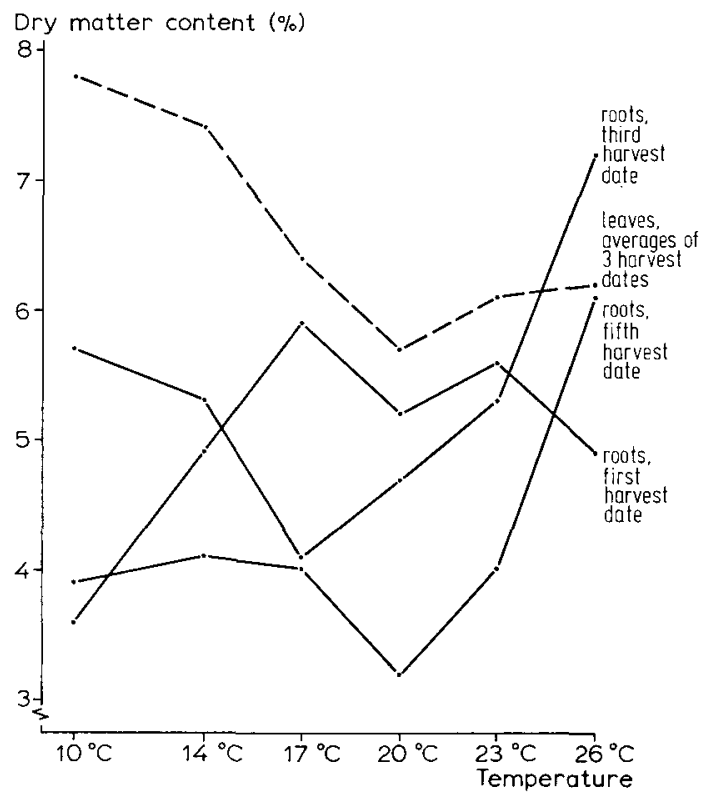

Fig. 4. Effect of temperature and harvest date on dry matter content of leaves and roots (averages of 3 cultivars). 
of the leaves decreased from 7.8 at $10{ }^{\circ} \mathrm{C}$ to around $6 \%$ at the 3 highest temperatures. Of the leaves of 'Cherry Belle', 'Kader' and 'Rota', \% DM was on an average respectively $7.1,6.4$ and 6.3 .

The \% DM of the roots at the first and the third harvests was 5.0 and 5.4, respectively, and at the fifth harvest, when the roots were over-mature, 4.2. This value was on an average lowest at $20^{\circ} \mathrm{C}(3.3 \%)$ and highest at $26^{\circ} \mathrm{C}(6.1 \%)$, but a distinct interaction harvest date $\times$ temperature occurred: at the first harvest $\% \mathrm{DM}$ of the roots at 10 and $14{ }^{\circ} \mathrm{C}$ was lowest, and at the third and fifth harvests that of roots grown at intermediate temperatures.

Of the roots of 'Cherry Belle', 'Kader' and 'Rota', \% DM was on an average 5.8, 4.7 and 4.4 , respectively.

Total fresh and dry weight of leaves + roots

At all harvest dates it was found that for total fresh as well as total dry weight: $m\left(20^{\circ} \mathrm{C}\right)=m\left(23^{\circ} \mathrm{C}\right)>m\left(17^{\circ} \mathrm{C}\right)>m\left(26^{\circ} \mathrm{C}\right) \geqslant m\left(14{ }^{\circ} \mathrm{C}\right)>m\left(10^{\circ} \mathrm{C}\right)$.

\section{Discussion}

\section{Comparison of growth and development in autumn and summer}

As can be seen from Fig. 5, radish in summer grows faster, produces higher leaf and root weights and root/leaf ratios than radish in autumn (Nieuwhof, 1976). In summer the first plants were harvestable after 3 weeks and in autumn only after 3 months. This difference in growth rate will be related to the irradiance level (in summer longer days an higher light intensities). The total outdoor irradiance from emergence until maturity at optimal temperatures for root thickening was, however, in both seasons about the same, viz about $20 \mathrm{~kJ} / \mathrm{cm}^{2}$. This may imply that growth rate of radish roots is determined mainly by the amount of irradiance and

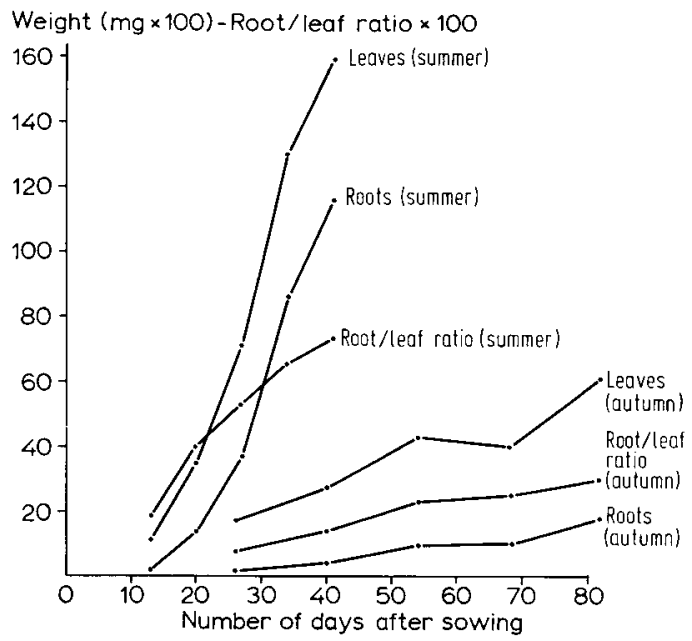

Neth. J. agric. Sci. $26(1978)$
Fig. 5. Growth of leaves and roots and root/leaf ratio in summer and autumn (Nieuwhof, 1976). Averages of 6 temperatures $\times 7$ cultivars/ strains. 
is more or less independent of day length. Banga \& van Bennekom (1962) also recorded no effect of day length on root thickening.

Temperature response for leaf production was in both seasons practically the same. In autumn as well as in summer the optimum was at about 20 to $23{ }^{\circ} \mathrm{C}$. For root thickening the optimum temperature was higher in summer than in autumn. In both seasons a shift of the optimum for root thickening during the experiment to lower temperatures was recorded, in the autumn from $14 \rightarrow 10^{\circ} \mathrm{C}$ and in the summer from $20 / 23{ }^{\circ} \mathrm{C} \rightarrow 17^{\circ} \mathrm{C} \rightarrow 14 / 10^{\circ} \mathrm{C}$. The shift to the lowest optimum temperature in the autumn occurred before the harvestable stage was reached and in the summer at a later date.

It was noted that the root/leaf ratio at maturity of the plants had been little influenced by the season. Both in autumn and summer this value was about 130 for the mature radish plants harvested at $10^{\circ} \mathrm{C}$.

Effect of harvest date and temperature on dry matter content in autumn and summer The \% DM of leaves and roots were about at high in summer as in autumn. Thus the faster growth in summer is not coupled with a lower \% DM, and caused by a more rapid dry matter production. In both seasons \% DM of 'Cherry Belle' was higher than that of 'Kader' and 'Rota'.

The effect of harvest date and temperature on $\% \mathrm{DM}$ of the leaves was different for both seasons: in autumn an increasing \% DM at later harvest, but not in summer, and in summer a decreasing \% DM at higher temperatures, but not in autumn. These different reactions may be related to the higher growth rate of the leaves in summer, reducing the chance that a certain production of dry matter will result in a higher or equal \% DM. Also the larger transport in summer of carbohydrates to the roots may play a role.

In the autumn trial \% DM of roots increased and weight of roots decreased at higher temperatures. This negative correlation between \% DM and weight of the roots was also found in the summer trial; at the third harvest date, for example, the lowest \% DM occurred at intermediate temperatures, where the roots were biggest, but some exceptions also occurred. At the first harvest date of the summer trial the roots at 10 and $14{ }^{\circ} \mathrm{C}$ were small, yet their \% DM was low. This may be caused by the low leat area of the plants at these temperatures, owing to which transport of carbohydrates to the roots will be restricted. Above a certain root size no correlation with \% DM existed: at the last harvest of the summer trial \% DM of the roots at 10,14 and $17{ }^{\circ} \mathrm{C}$ with a weight of 14 to $16 \mathrm{~g}$ was as low as that of the roots at 20 and $23{ }^{\circ} \mathrm{C}$ with a weight of 9 to $10 \mathrm{~g}$, but \% DM of the roots at $26{ }^{\circ} \mathrm{C}$ with a weight of about $5 \mathrm{~g}$ was clearly higher.

\section{Genotype $\times$ environment interaction}

The order for leaf and root weight of the cultivars in summer was practically the same as in autumn. Fast growers in autumn were also fast growers in summer. Thus no distinct interactions cultivar $\times$ season were found. It must be emphasized, however, that this holds true for the material included in both these experiments. Most of these cultivars, with the exception of 'Champion', are closely related and used 
for early glass or outdoor production. It is conceivable that more pronounced interactions would occur if more distinct radish types were involved, especially such as react differently to day length. The interactions found in the summer experiment between cultivars on the one hand and harvest time and temperature on the other occurred mainly after most cultivars had already reached the harvestable stage, and are therefore less important from the viewpoint of selection.

In our breeding research on radish the possibilities are investigated to improve growth rate in autumn and winter, using as parent populations the same types as tested in the experiments here described. As practically no cultivar $X$ season interactions occur between these early types selection may also be carried out in summer. An advantage is that in summer the growing period is much shorter than in autumn and that selection can be made in outdoor crops. A drawback, however, is that seed production of radish plants selected in summer is more complicated, because such plants flower in late summer and autumn. For a good seed production of these plants a heated glasshouse and artificial illumination may be needed, in contrast to plants which are selected in autumn, overwintered in frost-proof glasshouses and bolt and flower the next spring and summer.

\section{References}

Banga, O. \& J. L. van Bennekom, 1962. Breeding radish for winter production under glass. Euphytica 11: 311-326.

Nieuwhof, M., 1976. The effect of temperature on growth and development of cultivars of radish under winter conditions. Scientia Hort. 5: 111-118. 